\title{
Unobserved preferences and dynamic platform pricing under positive network externality
}

\author{
Hannu Huuki ${ }^{1,2}$ (D) Rauli Svento $^{1}$
}

Accepted: 31 October 2020 / Published online: 29 December 2020

(C) The Author(s) 2020

\begin{abstract}
We study the dynamic optimization of platform pricing in industries with positive direct network externalities. The utility of the network for the consumer is modeled as a function of three components. Platform price and participation rate affect the consumer's decision to join the platform. The platform operator is assumed to know the consumer's sensitivities with respect to these components. In addition, the consumer's utility is a function of other attributes, such as network privacy policies and environmental effects of the service. We assume that the distribution of these unobserved preferences in the potential customer base is known to the platform operator. We show analytically how the unobserved preferences affect the dynamic platform price design. Both static and rational expectations with respect to the platform participation are presented. We simulate an electricity market demand side management service application and show that the platform operator sets low prices in the launch phase. The platform operator can set higher launching prices if it can affect customers' preferences, expectations or adjustment friction.
\end{abstract}

Keywords Dynamic pricing $\cdot$ Network externality $\cdot$ Unobserved preferences $\cdot$ Electricity market $\cdot$ Demand side management

JEL classification $\mathrm{L} 11 \cdot \mathrm{L} 14 \cdot \mathrm{D} 85 \cdot \mathrm{C} 61 \cdot \mathrm{Q} 41$

"Successful strategies in a positive-feedback industry are inherently dynamic." [25]. Information Rules.

Hannu Huuki

hannu.huuki@oulu.fi

1 Oulu Business School, Department of Economics, Accounting and Finance, University of Oulu, P.O. Box 4600, 90014 Oulu, Finland

2 Finnish Environment Institute, University of Oulu, P.O. Box 413, 90014 Oulu, Finland 


\section{Introduction}

Pricing decisions in industries with positive network externalities require careful analysis. A classic example of network externality is a communications service, where the utility of each user increases as more users join in. Rolfs [22] describes the importance of a direct network effect as follows: "This is a classic case of external economies in consumption and has fundamental importance for the economic analysis of the communications industry". Today, the rise of digital platforms, which mediate the interaction of different user groups, highlights the role of economics in understanding positive feedback and optimal pricing in the network economy [25].

For a profit maximizing monopolist, the main implications of positive network externality for the optimal price setting can be summarized as follows: first, pricing depends on how the consumers value the network externality and on consumers' price sensitivity of demand; second, the price is set according to network size and is thus dynamic by nature, and third, the distribution of consumers' unobserved preferences related to the service the network provides has a great impact on the dynamic price profile [27].

In this article, we focus on the dynamic optimization of platform pricing in industries with positive direct network externalities. The utility of the network for the consumer is modelled as a function of three components. Both the platform price and the network size (participation) affect the consumer's decision to join the platform and the platform operator is assumed to know the consumers' sensitivities with respect to these components. Thirdly, the consumer's utility is a function of other attributes, such as network privacy policies and environmental effects of the service. We assume the platform operator knows the distribution of these preferences in the potential customer base. Our modeling results concentrate especially on the role of these unobserved preferences $^{1}$ in optimal platform pricing.

As an illustrative example, dynamic pricing of an electricity demand side management service (DSM) is simulated. The DSM service provider has a better view of the total electricity demand the larger the network size (pool of households) is. This is because the demand forecast errors of a single household cancel each other. Thus, the positive network effect in the DSM network arises from the improved forecasting ability of the service provider. We quantify the effect of unobserved preference distribution, consumer expectations and participation demand friction on the optimal pricing and on the network's value. We draw general conclusions based on both analytical and simulation results.

The structure of the paper is the following: related literature is presented in Section 2; a platform pricing model is presented in Section 3; a DSM service provider's pricing example is presented in Section 4; conclusions end the paper in Section 5.

\footnotetext{
${ }^{1}$ Research on heterogeneous and unobserved preferences has rapidly proceeded in empirical economics after the seminal studies of Greene [10,11] and Train [26]. Kopsakangas-Savolainen and Svento (2011) make a summary of unobserved heterogeneity estimation in stochastic frontier models.
} 


\section{Literature}

A positive feedback effect is common in the early evolution phases of industries. Shapiro and Varian [25] explain the difference between the traditional supply-side economies of scale, related to larger firms having lower production costs, and network economies of scale, related to customers valuing products with a larger user base. Whereas positive economies of scale in traditional industries had natural limits which restrained the dominance of a single firm (e.g. the complexity of managing large organizations), the positive feedback effect in information economy with network externalities may lead to a single firm dominating the market (winner-take-all market). Importantly, consumers' expectations play a major role in the information economy. A product or service will become popular, if consumers expect it to be popular.

Network economics and two-sided markets have a strong research track. Rochet \& Tirole [21] define multi-sided markets as the markets where the price structure has an impact on the volume of transactions. The platform can set different types of fees for its members and these have different kinds of effects. Variable fees affect the willingness to trade after the member of either side has decided to join the platform. Fixed fees affect the willingness to join the platform. Rochet and Tirole [20] study a two-sided market with only transactions-related benefits and pricing, i.e., membership fees are discarded. Armstrong [1] studies the case when the platform incurs a cost from each joining member. Weyl [29] opens the question of heterogeneity of members on both sides. The members now have both individual interaction and member benefits.

Most of the academic literature of platform strategies analyzes pricing and network externalities in static models. However, platform businesses face the initial mass hurdle in their initial stage [6]. Cabral [3] summarizes related literature in dynamic network modeling. Doganoglu [4] and Mitchell and Skrzypacz [17] derive the Markov perfect equilibrium in an infinite-period game where consumers' utilities are increasing functions of past market shares of both sides. Quality of platform products is naturally important for network externalities. Markovich and Moenius [15] develop a model where consumers live for two periods and receive benefits through indirect qualityrelated network effects. In these models, consumers are short-sighted / myopic. Cabral's [3] own model is an overlapping generations model with forward-looking consumers, which make their choices sequentially. Forward-looking agents are also modeled, e.g., in papers by Fudenberg and Tirole [8] and Zhu and Iansiti [30].

Veiga [27] studies the dynamic price design in a market with positive network externalities between consumers and shows how the form of the preference distribution affects the platform's dynamic pricing decision. Comparing welfare maximizer and profit maximizer outcomes, Veiga [27] shows that the introductory fee of the platform is negative and below the steady-state price. This is because a new platform with no users has low value for the consumers (see also the "failure to launch" discussion in [6]). The effect of a new platform member is two-fold. First, because of the positive network externality, new platform members are easier to attract. Second, further membership expansion is more challenging, since the pool of potential members has decreased. The unique steady state condition requires that the second effect dominates the first. The same intuition applies also in our platform model.

We deepen the dynamic unobserved preferences analysis by illustrating how the shape of the preference distribution affects the platform's optimal pricing decision and 
value over the share of members. In our model, the platform sets a fixed fee and meets a heterogeneous customer base, where the potential customers differ on their unobserved preferences. We model platform pricing under both static and forward-looking (rational) expectations.

Our application relates to platforms using above-mentioned possibilities in electricity markets. Digitalization enables platform applications to emerge also in electricity networks. Smart grids can use platform services for several reasons (see e.g. [28]). Mainly, the intermittency problem related to renewable energy sources creates a need for retailers to find consumers willing to adjust their consumption according to supply conditions [16]. Electricity networks are a challenging area for demand-side platform services for two reasons. Unlike in telecommunication platform services, there are diminishing scale effects with respect to a higher share of flexible demand-side customers [13]. In addition, as Richter and Pollit [19] and Ruokamo et al. [23] show, even though consumers are interested in different types of dynamic contracts and automated management of their homes, they also need sizable compensations for this type of participation.

\section{Model}

In this section we show how the price sensitivity of the participation rate is related to the probability density function of the heterogeneous unobserved preferences of potential participants. We solve the optimal pricing policy under static and rational expectations. We show that compared to the static consumer expectations scenario, under rational expectations the price sensitivity of participation is amplified by a factor that is defined by the participation adjustment rate, marginal change of platform externality and the density of the unobserved preferences. We introduce the model and discuss the equilibrium in Section 3.1. The dynamic model with static expectations is presented in Section 3.2. Rational expectations are assumed in Section 3.3. The model follows the setup presented in Veiga [27].

\subsection{Static model}

Assume there is a unit mass of households. The platform participation rate is $q$. The externality function $f(q)$ captures the positive network effect, i.e., members view the platform more valuable the higher the participation rate is: $f(q)>0, f(q)>0$.

The platform operator knows the probability density function (pdf) $\phi$ of the households' unobserved preferences $\varepsilon$. The platform operator now sets a fixed membership fee $p$. The utility of the household, if it participates in the platform, is

$$
u=-p+f(q)-\varepsilon
$$

Household $i$ participates in the platform, when the utility of the membership is positive

$$
u_{i}>0 \Rightarrow-p+f(q)>\varepsilon_{i}
$$


The participation rate is set by the fixed-point equation:

$$
q=\Phi(-p+f(q))
$$

where $\Phi$ is the cumulative distribution function of unobserved preferences $\varepsilon$.

Participation sensitivity with respect to the participation rate $q$ can be derived as:

$$
\frac{\partial \Phi(-p+f(q))}{\partial q}=\phi f^{\prime}
$$

By definition, $\phi f>0$, given the positive network externality function. In addition, assume that the participation sensitivity is smaller than one, $\phi f<1$. Let $a, b \in \mathbb{R}$ arbitrary. According to the mean value theorem, there exists $c \in(a, b)$, such that

$$
\left(\phi f^{\prime}\right)(c)=\frac{\Phi(\mathrm{b})-\Phi(\mathrm{a})}{b-a} \leq \frac{|\Phi(\mathrm{b})-\Phi(\mathrm{a})|}{|b-a|}<1 \Leftrightarrow|\Phi(\mathrm{b})-\Phi(\mathrm{a})|<|b-a| .
$$

Thus, the Banach fixed-point theorem can be applied, such that there exists $q^{*}$ with $q^{*}=\Phi\left(-\mathrm{p}+\mathrm{f}\left(q^{*}\right)\right)$ if $\mathrm{p}$ is fixed.

From the fixed-point equation

$$
q=\Phi(-\mathrm{p}+\mathrm{f}(\mathrm{q})) \Leftrightarrow 0=q-\Phi(-\mathrm{p}+\mathrm{f}(\mathrm{q}))=R(q, p)
$$

since $R(p, q)=0$, we can derive the implicit function $q(p)$ by

$$
\frac{\partial q}{\partial p}=-\frac{R_{p}}{R_{q}}=-\frac{\partial_{p}[q-\Phi(-p+f(q))]}{\partial_{q}[q-\Phi(-p+f(q))]}=-\frac{\phi}{1-\phi f^{\prime}} .
$$

Assumption $1-\phi f>0$ implies that platform demand is decreasing in price $(\partial q / \partial p<0)$. The density function of unobserved preferences $\phi$ is sufficiently diffused compared to the positive network externality: $\phi<1 / f^{\prime}$ (see [27]). Next, we show how the density function $\phi$ affects the dynamic price design.

\subsection{Dynamic pricing, static expectations}

Two components are added to introduce dynamics into the model. First, we add a discrete time index $t, t \in\{1,2, \ldots\}$. Second, we introduce a participation adjustment factor $s \in[0,1]$ to the model. The adjustment factor measures the share of households which, based on their preferences, make an active decision to participate or not to participate in the platform. Assuming $s<1$ introduces participation adjustment friction to the model and describes a partial attention towards the platform service. Acquiring complete information about the service can be costly. Thus, full attention with respect to the utility of platform membership can be an unrealistic assumption.

Assume firstly that households have static expectations. They view the utility of the platform in period $t$ as a function of the participation rate in period $t-1: f\left(q_{t-1}\right)$. Then, in period $t$, given that the platform price is $p_{t}$, the share of households willing to join the 
platform, $w_{t}$, is

$$
w_{t}=\Phi\left(-p_{t}+f\left(q_{t-1}\right)\right) \text {. }
$$

The participation adjustment factor $s$ implies that the actual change in participation rate $\Delta q_{t}$ evolves according to

$$
\Delta q_{t}=q_{t}-q_{t-1}=s\left(w_{t}-q_{t-1}\right)
$$

Assume the platform membership incurs no costs for the operator. We can write the platform operator's profit maximization problem as follows

$$
\max _{p_{t}} \sum_{t=1}^{\infty} p_{t} q_{t}\left(q_{t-1}, p_{t}\right)
$$

such that

$$
q_{t}\left(q_{t-1}, p_{t}\right)=q_{t-1}+s\left(\Phi\left(-p_{t}+f\left(q_{t-1}\right)\right)-q_{t-1}\right) .
$$

Equations 10 and 11 can be written in the recursive form as

$$
V\left(q^{\text {prev }}\right)=\max _{p} p q+\beta V(q)
$$

where

$$
q\left(q^{\text {prev }}, p\right)=q^{\text {prev }}+s\left(\Phi\left(-p+f\left(q^{\text {prev }}\right)\right)-q^{\text {prev }}\right) .
$$

Equation 12 is the Bellman equation, which shows that the operator's policy variable is the platform price $p$ and the state variable is the previous period's participation rate $q^{\text {prev }}$. Equation 13 is the transition equation of the state variable.

The platform operator's revenue maximization first order condition is

$$
\frac{\partial V\left(q^{\text {prev }}\right)}{\partial p}=p \frac{\partial q}{\partial p}+q+\beta \frac{\partial V(q)}{\partial q} \frac{\partial q}{\partial p}=0,
$$

where the price sensitivity of participation is

$$
\frac{\partial q}{\partial p}=-s \phi\left(-p+f\left(q^{p r e v}\right)\right) \leq 0 .
$$

Equation 15 shows that the price sensitivity of the participation rate is related to the probability density function of the unobserved preferences. Figure 1 illustrates this connection. A marginal increase (decrease) in the platform price decreases (increases) the participation rate by $\phi s$.

Equations 14 and 15 reveal the trade-off that the platform operator considers in the optimal price setting: 


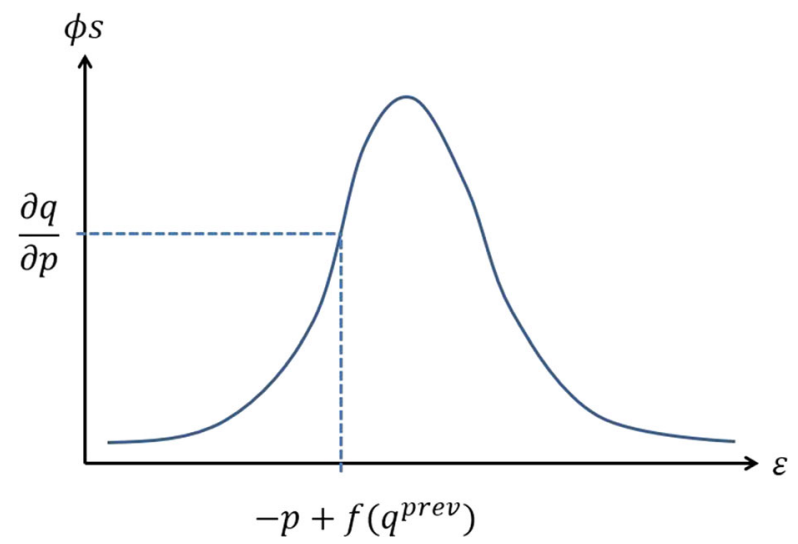

Fig. 1 Probability density function of unobserved preferences $(\varepsilon)$ and the sensitivity of platform participation rate

$$
q=(\phi s)\left[p+\beta \frac{\partial V(q)}{\partial q}\right]
$$

Equation 16 shows that the platform price is set so that the marginal benefit of a price change equals its marginal cost. Say the platform operator considers a marginal increase in price $p$ in the current period. The left-hand side shows the marginal benefit. The platform receives extra revenue from all the participants $(q)$. The right-hand side shows the marginal cost of the price change. The platform participation decreases by $(\phi s)$ and the platform loses the payment $(p)$ in the current period and the discounted value $\left(\beta \frac{\partial V(q)}{\partial q}\right)$ in the following period from these potential participants.

Equation 16 highlights the importance of the price sensitivity of participation $(\phi s)$ in the optimal dynamic platform pricing. Consequently, knowledge of the shape of the unobserved preferences density function $(\phi)$ provides an important insight into the platform pricing design phase.

\subsection{Dynamic pricing, rational expectations}

Assume next that the potential platform members have perfect understanding about the platform pricing and participation rate adjustment dynamics. When a potential new customer or a current platform member receives information about the platform participation rate $q^{\text {prev }}$ at the end of period $(t-1)$ and the current platform price $p$, they can correctly assess the positive network externality in period $t: f\left(q\left(q^{\text {prev }}, p\right)\right)$. The recursive optimization problem is

$$
V\left(q^{\text {prev }}\right)=\max _{p} p q+\beta V(q),
$$

where

$$
q\left(q^{\text {prev }}, p\right)=q^{\text {prev }}+s\left(\Phi\left(-p+f\left(q\left(q^{\text {prev }}, p\right)\right)\right)-q^{\text {prev }}\right) .
$$


The platform operator's first order condition is similar with Equation 14 under static expectations,

$$
\frac{\partial V\left(q^{\text {prev }}\right)}{\partial p}=p \frac{\partial q}{\partial p}+q+\beta \frac{\partial V(q)}{\partial q} \frac{\partial q}{\partial p}=0,
$$

but the price sensitivity of participation differs from Equation 15. Based on the Implicit Function Theorem and the use of implicit differentiation, we can write the price sensitivity as

$$
\frac{\partial q}{\partial p}=-\frac{-s(-1) \phi}{1-s f^{\prime} \phi}=-\frac{1}{1-s f^{\prime} \phi} s \phi .
$$

Assumption $1-f \phi>0$ implies that $1-s f \phi>0$ as well, since $s \in[0,1]$. Thus, the demand is decreasing in price, $\partial q / \partial p<0$. Furthermore, $\left(\frac{1}{1-s f^{\prime} \phi}\right)>1$, under the fixedpoint assumption, $\phi f<1$. Compared to the price sensitivity under static expectations in Equation 15 , factor $\left(\frac{1}{1-s f^{\prime} \phi}\right)$ amplifies the price sensitivity of participation under rational expectations.

Equations 19 and 20 reveal the trade-off that the platform operator considers in the optimal price setting under rational consumer expectations:

$$
q=\left(\frac{1}{1-s f^{\prime} \phi}\right)(\phi s)\left[p+\beta \frac{\partial V(q)}{\partial q}\right] .
$$

Equation 21 shows that the optimal price is set, such that the marginal benefit (left-hand side) equals the marginal cost (right-hand side) of a price change. The difference to static consumer expectations (see Equation 16) is that under rational consumer expectations the price sensitivity of participation is amplified by the factor of $\left(\frac{1}{1-s f^{\prime} \phi}\right)$.

\section{Dynamic pricing of an electricity demand-side management service}

Based on digitalization, electricity markets have turned into two-sided markets where consumers can actively react to real-time prices and feed their own distributed production back to the net (e.g. [14]). At the same time renewables are gaining market shares and create the intermittency problem [9, 12]. Demand side management (DSM) has been suggested as one solution to the intermittency problem. DSM refers to changes in the timing or in the level of electricity consumption [13, 19].

In our application, the DSM service refers to a household's electricity consumption profile optimization in such a way that electricity costs are minimized, but the total consumption does not change. Changes in the electricity consumption are based on the changes in hourly electricity prices. For example, a residential customer can shift the household heating from a high-price period to a low-price period without a significant loss of comfort. The DSM operator optimizes the hourly electricity use of the household on behalf of the customer. 


\subsection{Network externality function in demand-side management services}

Assume that there is a potential DSM service customer pool of $\bar{q}=100$ households. Each household has a smart meter, which facilitates the integration of the household's heating system and the electricity price information of the electricity market. The DSM operator minimizes the total costs of electricity bought from the grid to upkeep the conformity levels in the participating households plus the imbalance costs it faces when these conformity limits cannot be met. We present the DSM optimization model and the annual costs over varying participation rates using actual Nord Pool data in Appendix 1.

Hourly electricity consumption $c_{h}^{i}$, with mean consumption rate $\mu_{h}$, of each household $\dot{i}, \dot{i} \in\{1,2, \ldots, \bar{q}\}$ in each hour $h \in\{1, \ldots, H\}$ is stochastic:

$$
c_{h}^{i}=\mu_{h}+\nu_{h}^{i} \text {, where } \nu_{h}^{i} \sim N\left(0, \varphi^{2}\right), \forall i=1, \ldots, \bar{q}, h=1, \ldots, H .
$$

Given the stochasticity, when the automated heating optimization is done separately for each household, the households pay on average $C(q=1)$ for the electricity annually. Alternatively, the DSM operator can optimize the households' electricity use and create value for the participants by pooling together a larger mass of households.

Assume the stochastic parts of hourly household electricity consumption realizations $\left(V_{h}^{i}\right)$ are independent. ${ }^{2}$ Consequently, if the DSM operator controls a larger pool of a household's $(q=2, \ldots, \bar{q})$ electricity usage, uncertainties related to the representative household's electricity consumption decreases. This is because the DSM operator provides electricity to a larger network and the consumption realization shocks occur at varying scale and direction (negative and positive) over the pool of households. According to the Central Limit Theorem, when the number of participating households is $q$, the average electricity consumption of a household in the network becomes:

$$
\bar{c}_{h}=\mu_{h}+\bar{v}_{h}, \text { where } \bar{v}_{h} \sim N\left(0, \frac{\varphi^{2}}{q}\right), h=1, \ldots, H .
$$

Given the reduced uncertainty, the DSM operator can allocate its members' electricity consumption more precisely according to the hourly electricity prices. This increases the savings from the DSM service: $C(q>1)<C(q=1)$. Consequently, in scenarios where more than a single household takes part in the DSM network $(q=2, \ldots, \bar{q})$, the network externality function $f(q)$ is positive (Fig. 2). Concavity $(f(q)<0)$ implies that the marginal benefit of additional members in the network is diminishing. If all the potential members join the network, the positive externality effect $f(\bar{q})$ brings $39.5 €$ savings in each participating household's annual electricity bill.

\footnotetext{
${ }^{2}$ Notice that this assumption applies to the use of electrical appliances and domestic hot water. In case of small-scale renewable energy generation like solar photovoltaics, the independence assumption does not apply when the households are in the same region.
} 


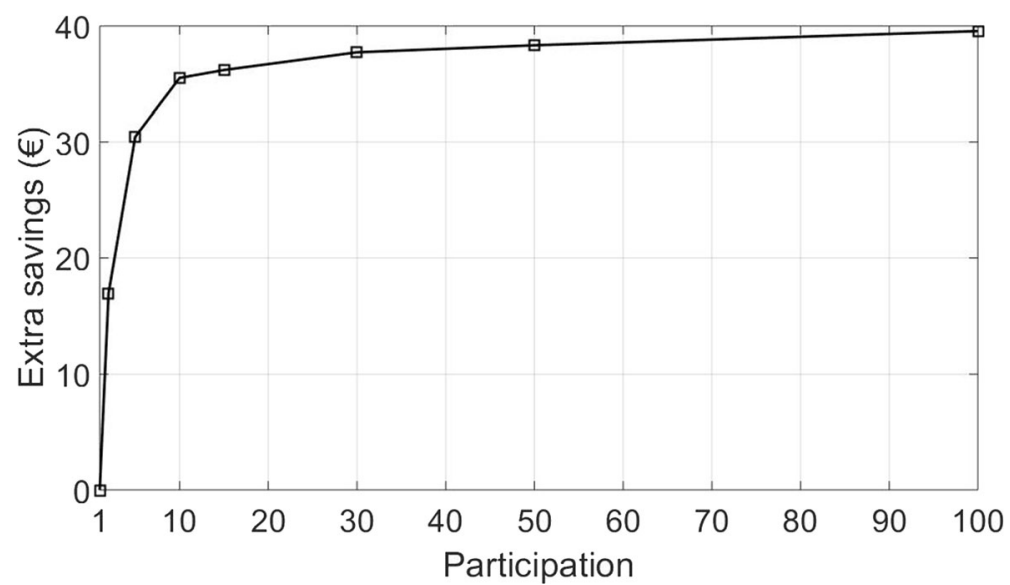

Fig. 2 Network externality function. The monetary benefit per household as a function of total household participation rate $q \in\{1,2, \ldots, \bar{q}\}, \bar{q}=100$

\subsection{Unobserved preferences of demand-side management customers}

Consumer preferences in demand management on the electricity market have been studied in several papers. Ruokamo et al. [23] study households' willingness to offer demand flexibility in electricity usage and heating. They show that households are more sensitive to restrictions in electricity usage than to restrictions in heating. Both Broberg and Persson [2] and Richter and Pollit [19] show that consumers demand compensation for participating in automated demand side management programs. In addition, Dütschke and Paetz [5] show that consumers prefer simple dynamic pricing programs to complex ones.

On the positive side, Ruokamo et al. [23] show that households value power system level reduction in $\mathrm{CO}_{2}$ emissions. However, large emission reductions are required for activating the demand flexibility potential. Schlereth et al. [24] show that price consciousness and age increase the switching probability from a time-invariant to a timevariant pricing plan. Consumers also value technical support [19] and the societal effects related to demand-side flexibility should be communicated to potential dynamic pricing program participants [5].

The heterogeneity in valuations for the electricity service contract attributes implies that consumer profiling can provide useful information in service contract design [19]. In our model, we introduce unobserved preferences through several scenarios by making assumptions on their distributions. The benchmark pdf $\phi$ of the unobserved preferences is set to be normal: $\mathrm{N}\left(\mu, \sigma^{2}\right)$. We set $\mu=0 €$, which implies that the unobserved preferences are distributed evenly on both sides of mean zero. We set $\sigma=f(\bar{q}) / 1.96$, which implies that $95 \%$ of the potential customers' unobserved preferences are located between $-f(\bar{q})=-39.5 €$ and $f(\bar{q})=39.5 €$.

In an alternative scenario, assume that household's attitudes towards DSM service become more favorable (Fig. 3). For example, consumers might appreciate the positive role of demand side flexibility in renewable energy integration in the electricity grid. Reference Scenario 1 implies that the unobserved preferences pdf moves to the left: 
$\mathrm{N}\left(\mu-\gamma, \sigma^{2}\right)$. We set $\gamma=10$, which implies that the mean of unobserved preferences is now $-10 €$. Given the price $p$ and participation rate $q$ combination, the share of households willing to join the platform, $w=\Phi(-p+f(q))$, is higher in Scenario 1 than in the benchmark scenario.

In a second scenario, assume that household's attitudes are uniformly distributed (Fig. 4). Reference Scenario 2 implies that the probability for each unobserved preference value is even: $\mathrm{U}\left(\varphi_{-}, \varphi\right)$. We set $\varphi=3 \sigma$, which implies the unobserved preferences are distributed between $-48.6 €$ and $48.6 €$. Given the price $p$ and participation rate $q$ combination, the share of households willing to join the platform is higher (lower) in Scenario 2 than in the benchmark scenario when $p+f(q)$ is low (high) (see cumulative distribution functions in Fig. 4, bottom).

\section{Optimal DSM pricing policies}

Using the above-presented assumptions of a household's expectations on the network size and distributions of unobserved preferences, we present the DSM service pricing policies and participation rates in this section. The platform operator's profit maximization problem follows Equations (12) and (13) under the static expectations and Equations (15) and (16) under the rational expectations. The Bellman equations are solved using policy iteration. Discrete time $t$ marks the annual time-steps and discrete state $q_{t}$ marks the number of households in the platform. We set the annual discount factor $\beta$ to 0.95 . The positive network externality, $f\left(q_{t}\right)$, describes the annual savings per household as a function of DSM service participation rate (see Fig. 2). The adjustment factor, $s$, is set to 0.5 . The unobserved preferences' density function, $\phi(\varepsilon)$, is assumed to be normal in the benchmark scenario.

In all the scenarios, we assume that the platform starts with zero members in year 0 : $q_{0}=0$. The platform chooses the prices for the following years $(t=1,2, \ldots)$ as a
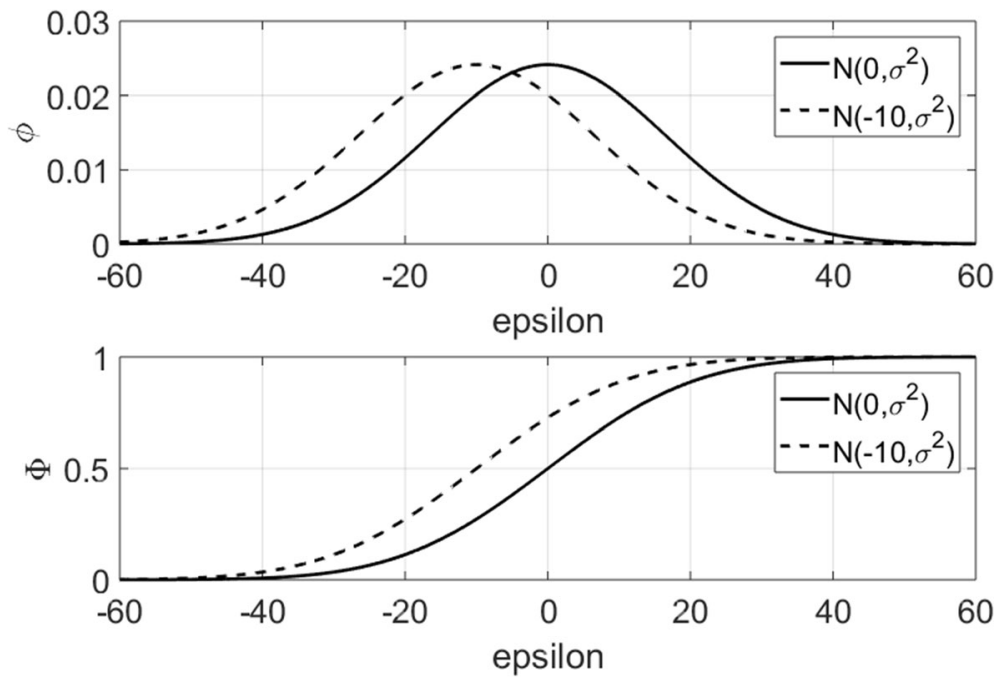

Fig. 3 Unobserved preferences. Benchmark scenario (solid) with mean zero and Scenario 1 (dashed) with mean $-10 €$ 

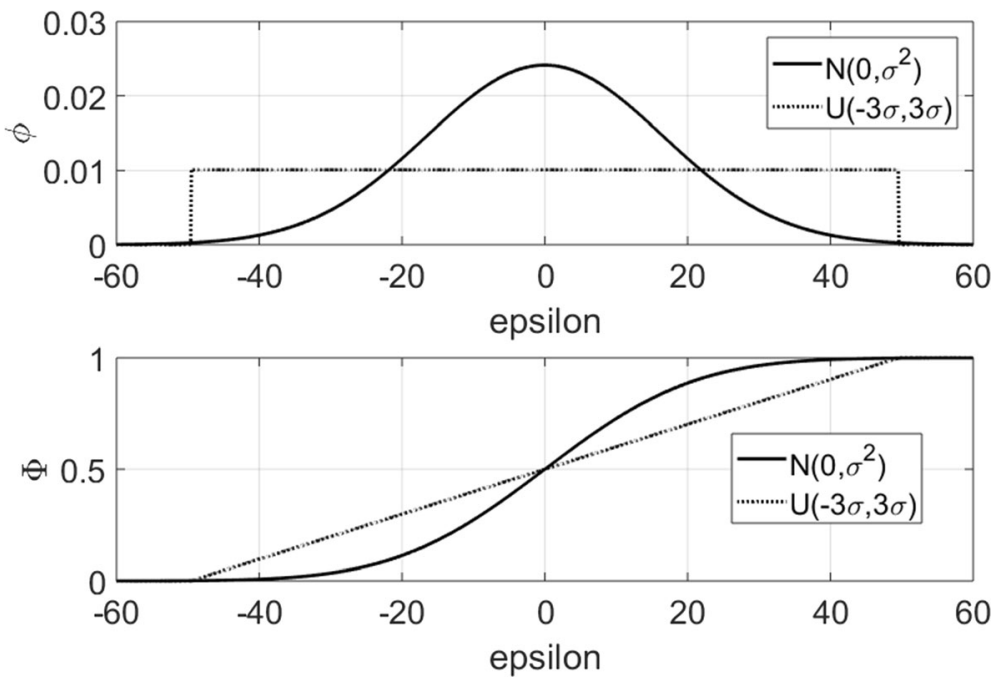

Fig. 4 Unobserved preferences. Benchmark scenario (solid) with mean zero and Scenario 2 (dotted) with uniform distribution

function of participation rate in the previous period: $p_{t}\left(q_{t-1}\right)$. We present the optimal pricing and participation paths over several scenarios (Table 1). In a static setting, the equilibrium participation rates over the fixed platform price are presented in Appendix 2.

We illustrate how the distribution of the unobserved preferences (Benchmark, Scenario 1, Scenario 2) affects the dynamic price setting in Section 5.1. The effect of expectations on pricing (Scenario 3) are presented in Section 5.2. We discuss the effect of the participation adjustment factor (Scenario 4 and Scenario 5) in Section 5.3. Platform launching prices, equilibrium prices and participation rates over the different scenarios are compared in Section 5.4.

\subsection{Pricing policy functions under unobserved preference distributions}

Policy functions with normally distributed unobserved preferences are presented in Fig. 5. In the benchmark scenario with distribution around mean zero (solid line), the platform operator subsidizes early adopters by setting the platform price below the

Table 1 Scenarios in DSM service application

\begin{tabular}{llll}
\hline & Expectations & Density function of $\varepsilon$ & Adjustment factor \\
\hline Benchmark & static & $N\left(0, \sigma^{2}\right)$ & $s=0.50$ \\
Scenario 1 & static & $N\left(-10, \sigma^{2}\right)$ & $s=0.50$ \\
Scenario 2 & static & $U(-3 \sigma, 3 \sigma)$ & $s=0.50$ \\
Scenario 3 & rational & $N\left(0, \sigma^{2}\right)$ & $s=0.50$ \\
Scenario 4 & static & $N\left(0, \sigma^{2}\right)$ & $s=0.25$ \\
Scenario 5 & static & $N\left(0, \sigma^{2}\right)$ & $s=0.75$ \\
\hline
\end{tabular}




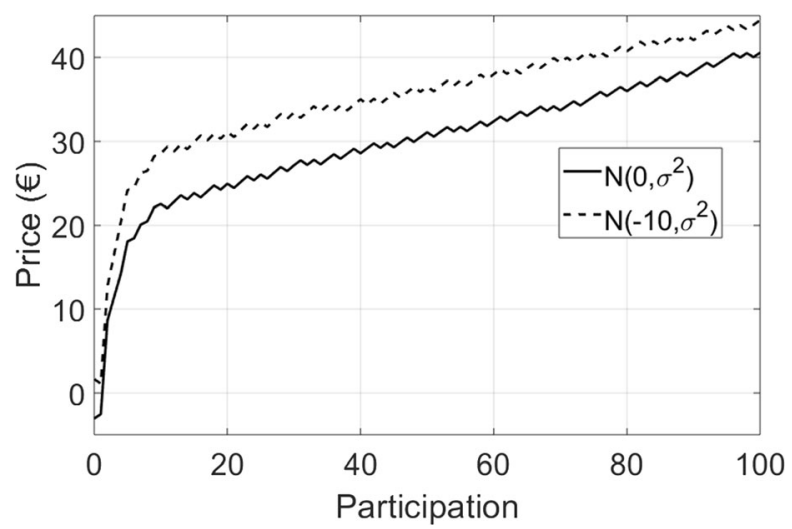

Fig. 5 Optimal pricing policy as a function of the participation rate $q$. Benchmark scenario (solid) with mean zero and Scenario 1 (dashed) with mean $-10 €$

zero-marginal cost. In Scenario 1, a favorable shift in households' preferences towards the platform attributes allows the platform to already charge a positive mark-up in the launching phase (dotted line).

Optimal pricing policy increases sharply as a function of the participation rate initially, but a flattening of the price increase after a certain participation is achieved. These policy functions describe the interaction between the sensitivity of platform participation (Fig. 1) and the concave network externality function (Fig. 2).

We illustrate how these policy functions translate into action in Fig. 6. The platform subsidizes early adopters with lower prices. From year 4 onwards the participation and pricing paths seem to stabilize. With favorable attitudes towards the DSM service, the platform can charge a higher participation fee to a larger member base.

In Scenario 2, with uniformly distributed unobserved preferences, the initial pricing can be more aggressive. Because the probability mass on the left of the distribution is larger with uniformly than with normally distributed preferences (see Fig. 4), the platform operator can set a higher price and still capture members in the launch stage. On the other hand, the long-run participation rate in Scenario 2 is below the

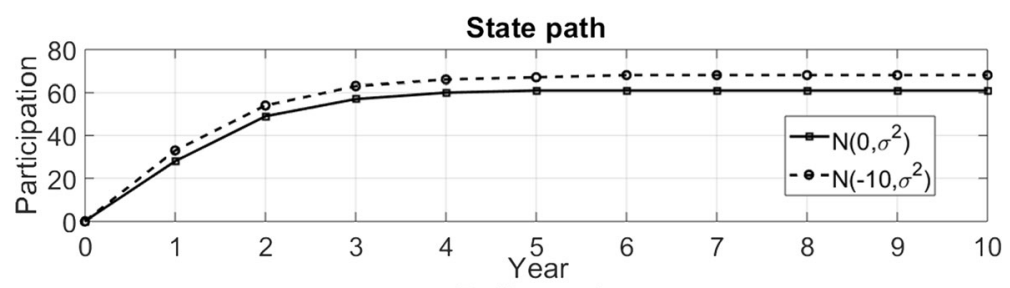

Policy path

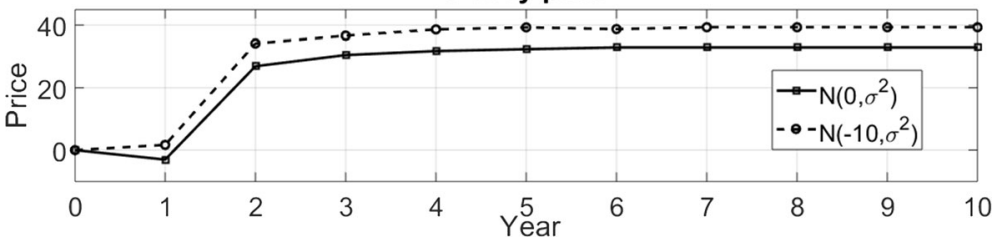

Fig. 6 State (top) and policy (bottom) paths. Benchmark scenario (solid) with mean zero and Scenario 1 (dashed) with mean $-10 €$ 
participation in the benchmark case. With uniform distribution, the platform cannot utilize the part of the cumulative probability function where the marginal increase in participation is high (Fig 7).

\subsection{Role of expectations for pricing policies}

In Scenario 3, we assume rational expectations. The optimal pricing policy differs between the static and rational expectation cases with low participation rates (Fig. 8). Under rational expectations the platform does not have to subsidize early adopters, since the households can reason through the whole chain of participation adjustment.

Figure 9 illustrates how expectations affect the state and policy dynamics in the launching phase, but the paths converge as the participation rate increases. When the consumers' expectations are rational, both the participation rate and platform price deviate less from their equilibrium values. Platform launching is smoother and more profitable, when the adjustment process can be communicated to the potential customer base.

\subsection{Role of the participation adjustment factor}

Platform participation adjustment factor $s$ is set to 0.50 in the benchmark scenario. This implies that, given the general information on the participation rate and the platform price and the private information on a household's other preferences, half of the customers willing to join or leave the platform under full attention do act in each period $t$. In Scenario 4 the participation adjustment factor is assumed to be 0.25 (more participation friction) and in Scenario 5 the factor is assumed to be 0.75 (less participation friction).

Figure 10 illustrates how the adjustment factor affects the pricing and participation rate dynamics. If the adjustment factor is high (less friction), the platform operator can set a higher price initially and the participation rate stabilizes faster. If the adjustment factor is low (more friction), the platform operator must subsidize early adopters heavily in the launching phase and adjust the price slowly towards the steady-state price level.
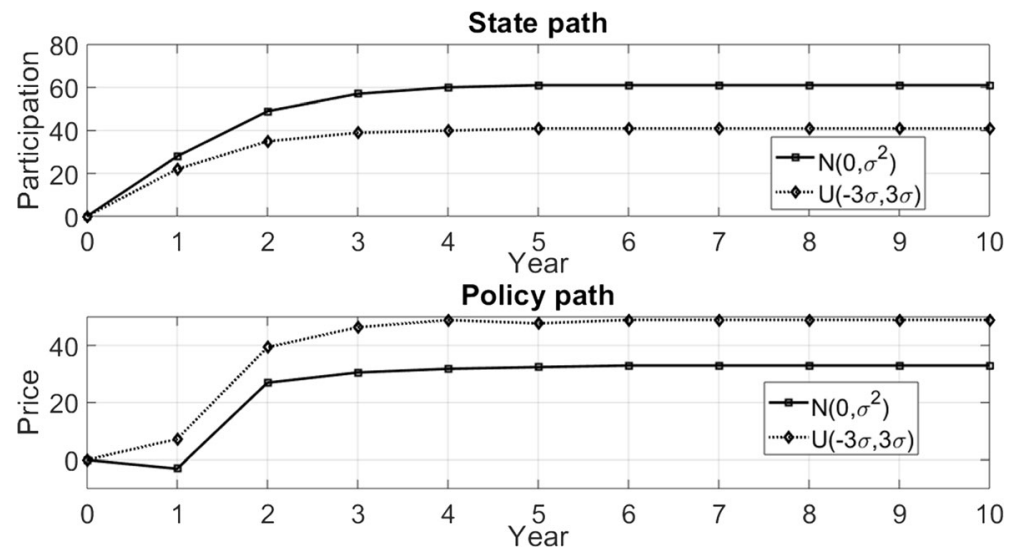

Fig. 7 State (top) and policy (bottom) paths. Benchmark scenario (solid) with mean zero and Scenario 2 (dotted) with uniform distribution 


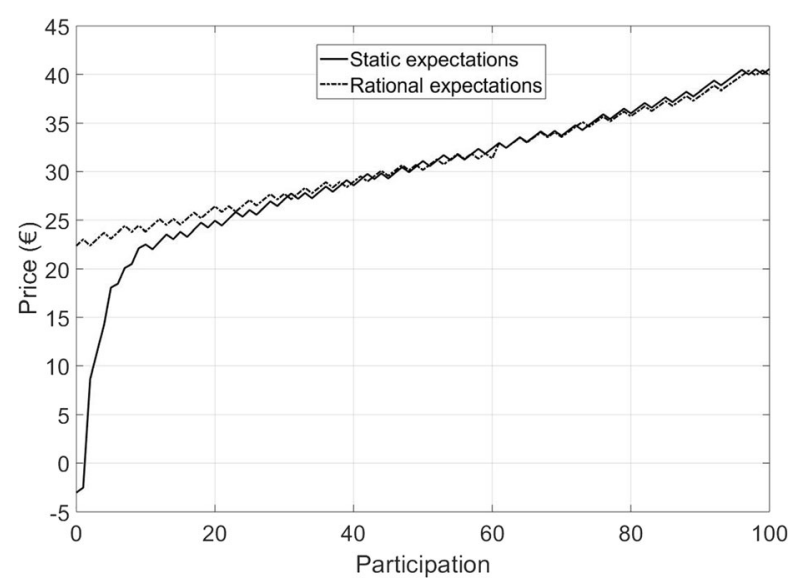

Fig. 8 Optimal pricing policy as a function of the participation rate $q$. Benchmark scenario (solid) with static expectations and Scenario 3 with rational expectations (dashed/dotted)

\subsection{Platform launching and equilibrium}

The main simulation results are collected in Table 2. The first column shows the assumption change in the model setup compared to the benchmark case. Initial platform prices, equilibrium prices and equilibrium participation rates are presented in the next columns. The final column shows the discounted sum of platform profits over the first 10 years of operation: $\pi=\sum_{t=1}^{10} p_{t} q_{t}$.

The DSM service subsidizes $\left(p_{0}<0\right)$ early adopters in the benchmark scenario and in Scenario 4 with higher participation friction. A high initial price can be set under rational consumer expectations. Thus, for a smooth launching, the DSM operator should try to inform the potential members about the positive network effect related to the service.
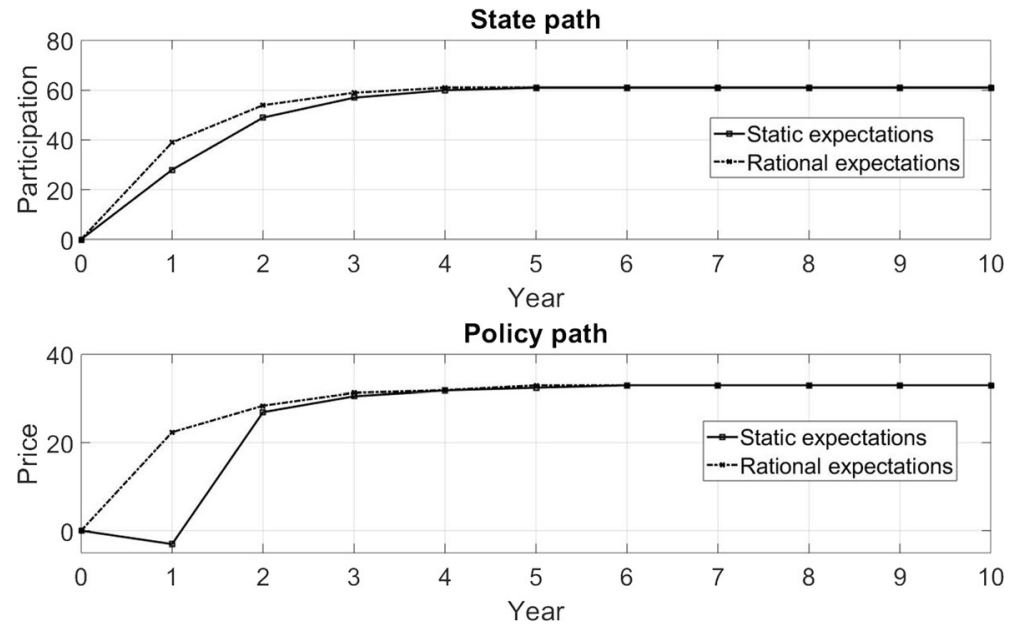

Fig. 9 State (top) and policy (bottom) paths. Benchmark scenario (solid) under static expectations and under rational expectations (dashed/dotted) 


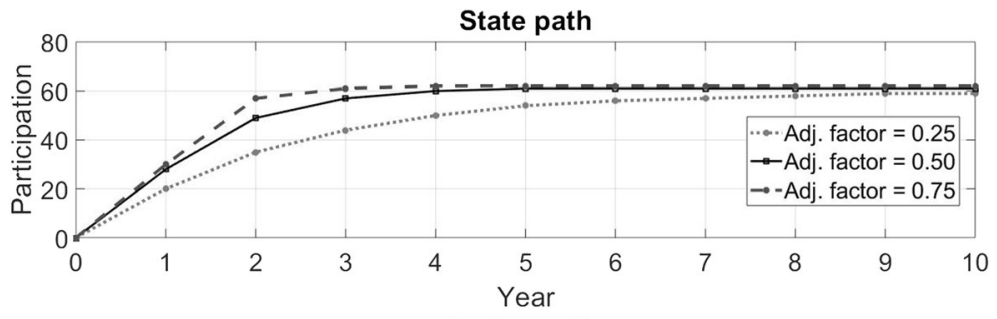

Policy path

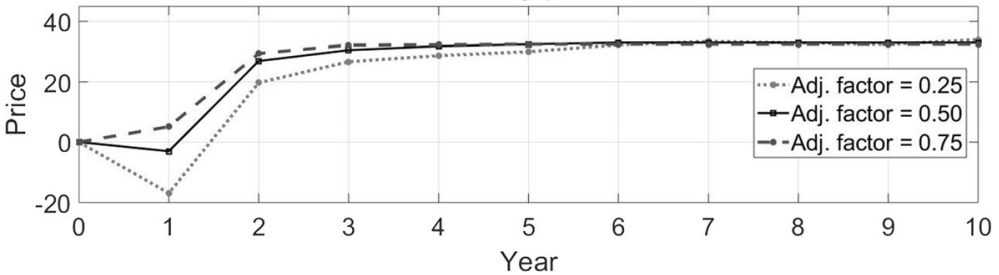

Fig. 10 State (top) and policy (bottom) paths. Benchmark scenario (solid) with adjustment factor $s=0.50$, Scenario 4 (light grey, dotted) with adjustment factor $s=0.25$ and Scenario 5 (grey, dashed) with adjustment factor $s=0.75$

Highest equilibrium price $p^{*}$ is set in Scenario 3, under uniform distribution of unobserved preferences. However, the equilibrium participation rate $q^{*}$ is the lowest in Scenario 3 and the cumulative profit $\pi$ is only slightly higher than in the benchmark scenario. The DSM operator achieves the highest cumulative profit in Scenario 1, where consumers' attitudes towards the service attributes are more favorable. The increased attention towards climate change may thus favour DSM services, provided that the service provider can explain the environmental aspects related to the service to the customers (e.g. that the demand side flexibility enables a share of higher renewable energy sources in the electricity system).

\section{Conclusions}

In this article we analyze the dynamic platform pricing with positive direct network externalities. We show analytically that the price sensitivity of participation rate is related to the probability density function of the unobserved preferences, the participation adjustment factor, the network externality function and the consumers'

Table 2 Launching price $p_{0}$, equilibrium price $p^{*}$, equilibrium participation rate $q^{*}$ and platform profit $\pi$

\begin{tabular}{llrrrl}
\hline & Assumption change & $p_{0}(€)$ & $p^{*}(€)$ & $q^{*}$ & $\pi(€)$ \\
\hline Benchmark & - & -3.05 & 32.96 & 61 & 10,609 \\
Scenario 1 & $N\left(-10, \sigma^{2}\right)$ & 1.67 & 39.34 & 68 & 14,322 \\
Scenario 2 & $U(-3 \sigma, 3 \sigma)$ & 7.26 & 48.95 & 41 & 10,946 \\
Scenario 3 & rational exp. & 22.37 & 32.96 & 61 & 11,796 \\
Scenario 4 & $s=0.25$ & -16.98 & 33.95 & 59 & 8410 \\
Scenario 5 & $s=0.75$ & 5.11 & 32.45 & 62 & 11,411 \\
\hline
\end{tabular}


expectations. We illustrate the effect of these components on platform pricing through a launch of an electricity market demand-side management service application.

Our results show that prior knowledge about the shape of the unobserved preferences distribution gives valuable insight for the platform pricing design, especially during the launching phase. An interesting avenue for further study is how to set the platform price in the model-free environment, when the operator has no initial knowledge about the consumer preferences. Optimization of the platform pricing exploration/ exploitation strategy in the launching phase is required when the transition model is not known to the platform operator.

In the generic setting, the platform operator balances the lost revenue from the existing participants with the increased revenue potential of new participants resulting from a marginal price decrease. The simulation results show that in the benchmark case, the platform operator is willing to accrue negative revenue in the launching phase to gain a larger participation rate later. If the unobserved preferences are more evenly distributed or the participation friction is lower, the platform operator can launch the service with a positive platform price and still achieve an increasing participation path for the platform.

In addition, we show that under rational consumer expectations the platform price can be set higher in the launching phase than under static consumer expectations. How consumers form the expectations about the network utility is related to the nature of the industry. For example, consumer expectations about the platform's utility might be more rational in social networking applications than in technical applications, such as the demand-side management in the electricity markets. When the consumer expectations are static, the platform operator has to subsidize the early adopters in order to make the utility of the platform visible to the potential customer base. Consumers' views about the participation adjustment process in industries with network externalities is an interesting research question for future studies.

Funding Open access funding provided by University of Oulu including Oulu University Hospital. Funding from the Academy of Finland Strategic Research Council project BCDC Energy (AKA292854) and Academy of Finland project EcoRiver (323810) is gratefully acknowledged. We thank two anonymous reviewers whose comments helped to clarify the article.

\section{Appendix 1. Demand-side management optimization}

The demand-side management (DSM) operator's optimization problem can be presented as follows. The DSM operator aims to minimize the participating households' total electricity costs. Positive network effect in this application arises from the reduced demand uncertainty on the aggregate level. The main results, costs and extra savings as a function of participation rate, are presented after the model specification.

Time $h$ is discrete and refers to hour-of-year: $h=1, \ldots, H, H=8784$. We use the leap year 2016 data for electricity prices, so the number of days is 366 and the number of hours is 8784 . 


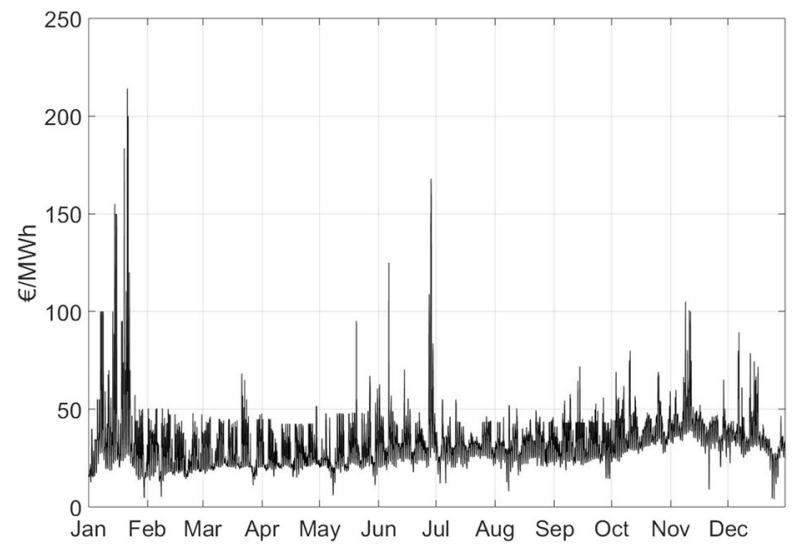

Fig. 11 Hourly electricity prices in Finland in 2016

The wholesale price of electricity varies hour-by-hour in the Nordic Elspot power market. Finland forms a single price area within the Nord Pool. Figure 11 illustrates the annual profile of hourly electricity prices in Finland in 2016 (data source: [18]).

Price statistics in Table 3 show that there exists price variation, which the DSM service provider can utilize in the participating households' electricity cost minimization.

The representative household's electricity consumption profile vector $\boldsymbol{e}$ represents hourly consumption in $\mathrm{kWh}$. The consumption vector is based on a typical load consumption profile for a household consuming at least $10,000 \mathrm{kWh}$ of electrical energy annually (see [7]). Different hourly consumption is set for each month and hour-of-day pair. Additionally, hourly consumption in workdays differs from the consumption in Saturdays and Sundays.

The total number of potential customers $i$ for the DSM service is $\bar{q}: i \in\{1,2, \ldots, \bar{q}\}$. We introduce a stochastic component to the deterministic consumption profile $\boldsymbol{\mu}$ by assuming that consumption shocks $\nu_{h}^{i}$ are drawn from a normal distribution with mean of zero and standard deviation $(\sigma)$ set to std. $(\boldsymbol{\mu})$. Households' hourly electricity consumption profiles follow

$$
c_{h}^{i}=\mu_{h}+\nu_{h}^{i} \text {, where } \nu_{h}^{i} \sim N\left(0, \sigma^{2}\right), \forall i=1, \ldots, \bar{q}, h=1, \ldots, H .
$$

Assume the consumption shocks $\nu_{h}^{i}$ are independent across households $i$ and hours $h$. The aggregated consumption uncertainty decreases when the DSM operator has a larger pool of households under operation, as the consumption realization shocks of the participating households cancel somewhat out each other. The number of

Table 3 Hourly electricity price statistics, 2016

\begin{tabular}{lllll}
\hline & mean & standard deviation & minimum & maximum \\
\hline electricity price $(€ / \mathrm{MWh})$ & 32.45 & 13.15 & 4.02 & 214.25 \\
\hline
\end{tabular}


households participating in the DSM operation is $q$. Based on the Central Limit Theorem, the average hourly electricity consumption of a participating household is:

$$
\bar{c}_{h}=\mu_{h}+\bar{v}_{h}, \text { where } \bar{v}_{h} \sim N\left(0, \frac{\sigma^{2}}{q}\right), h=1, \ldots, H
$$

In each hour, the DSM operator optimizes a household's hourly electricity usage from the grid $x_{h}$, before the consumption shock $\bar{v}_{h}$ is realized. The optimization can be done within specific cumulative energy limits: $\left[S_{-h}, S_{h}\right]$. These limits describe the optimization potential related to residential space and domestic hot water heating. We set the upper energy limit $S_{h}$ as $50 \%$ of the mean daily consumption and the lower limit $S_{-h}$ as $-S_{h}$.

As long as a household's indoor temperature and hot water temperatures are within set minimum and maximum bounds, the residents do not feel discomfort from the energy usage optimization. If the cumulative energy state $S_{h}$ exceeds the upper limit or falls below the lower limit, the DSM operator must make up the imbalance. The excess energy must be sold at a price below the hourly electricity price and the deficit energy must be procured at a price above the hourly electricity price.

The imbalance prices $p^{u p}$ and $p^{\text {down }}$ are calculated from the 2016 balancing market data. The average price difference between the balancing price and the spot price during the up-balancing hours is used for the up-balancing premium: $p^{u p}=18.74 € / M W h$. The average price difference between the balancing price and the spot price during the down-balancing hours is used for the down-balancing negative premium $-p^{\text {down }}=-$ $10.80 € / M W h$.

The DSM operator optimizes the representative household's hourly electricity use form the grid $x_{h}$, such that the total sum of energy cost and imbalance revenue over the annual period gets minimized

$$
\sum_{h=1}^{H}\left\{p_{h} x_{h}+\operatorname{ImRev}\left(S_{h}\right)\right\}
$$

The transition dynamics of the cumulative energy state $S_{h}$ is as follows

$$
\begin{gathered}
S_{-h} \leq S_{h}=S_{h-1}-c_{h}+x_{h} \leq S_{h}, \\
\bar{c}_{h}=\mu_{h}+\bar{v}_{h}, \\
\bar{v}_{h} \sim N\left(0, \frac{\sigma^{2}}{q}\right), h=1, \ldots, H .
\end{gathered}
$$


Table 4 Annual energy, imbalance and total costs in euros over a varying DSM service participation rate. The bottom row shows the annual savings $(€)$ related to the positive network effect

\begin{tabular}{crrrrrrrr}
\hline $\mathrm{N}$ & \multicolumn{1}{c}{1} & \multicolumn{1}{c}{5} & \multicolumn{1}{c}{10} & \multicolumn{1}{c}{15} & 30 & 50 & 100 \\
\hline Energy cost & 293.5 & 303.2 & 308.9 & 307.9 & 308.4 & 307.9 & 307.7 & 306.9 \\
Imbalance cost & 53.7 & 27.0 & 7.9 & 3.8 & 2.6 & 1.6 & 1.2 & 0.8 \\
Total cost & 347.2 & 330.2 & 316.8 & 311.7 & 311.0 & 309.5 & 308.9 & 307.7 \\
Savings compared to $N=1$ & & 17.0 & 30.4 & 35.5 & 36.2 & 37.7 & 38.3 & 39.5 \\
\hline
\end{tabular}

The imbalance revenue in hour $h$ is zero, when $S_{h}$ stays within the energy limits. If the cumulative energy state breaks the lower bound $S_{-h}$, the up-balancing price $\left(p_{h}+p^{u p}\right)$ must be paid for the energy deficit. If the cumulative energy state breaks the upper bound $S_{h}$, the down-balancing price $\left(p_{h}-p^{\text {down }}\right)$ is received from the excess energy. The imbalance revenue can be written as

$$
\operatorname{ImRev}\left(S_{h}\right)=\left\{\begin{array}{c}
0, \text { if } S_{-h}<S_{h-1}-c_{h}+x_{h}<S_{h}, \\
\left(p_{h}+p^{u p}\right)\left(S_{-h}-\left(S_{h-1}-c_{h}+x_{h}\right)\right), \text { if } S_{h-1}-c_{h}+x_{h}<S_{-h}, \\
\left(p_{h}-p^{\text {down }}\right)\left(\left(S_{h-1}-c_{h}+x_{h}\right)-S_{h}\right), \text { if } S_{h-1}-c_{h}+x_{h}>S_{h} .
\end{array}\right.
$$

Table 4 shows the annual total energy cost and the annual total imbalance revenue (positive value implies cost for the household). Higher participation rate $N$ decreases the household's imbalance costs and the total costs decrease. The last row of Table 4 shows the positive network externality, the increased savings from the optimization which are visualized in Fig. 2.

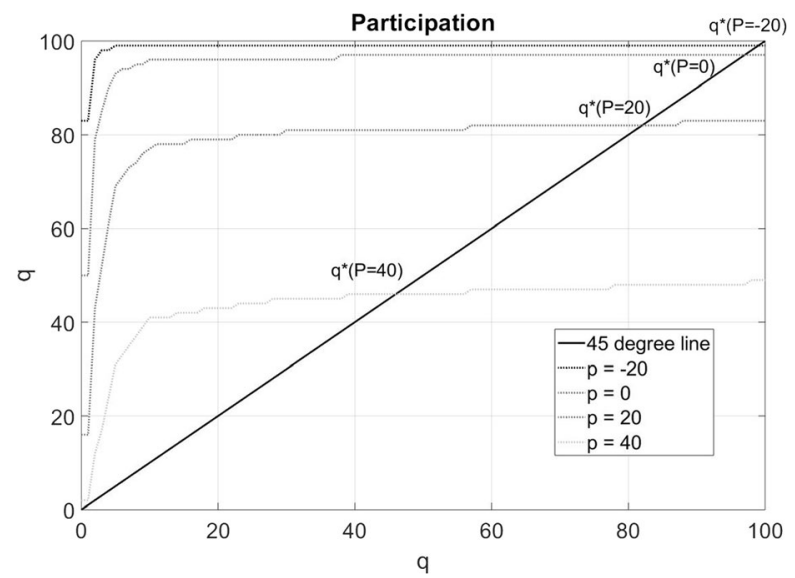

Fig. 12 Normal distribution of unobserved preferences: equilibrium participation rate as a function of the platform price 


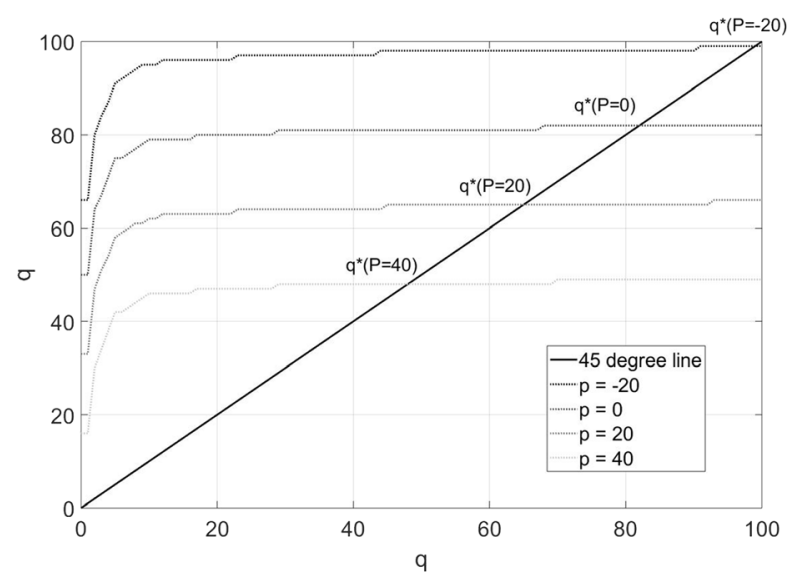

Fig. 13 Uniform distribution of unobserved preferences: equilibrium participation rate as a function of the platform price

\section{Appendix 2. Static analysis}

We present the equilibrium participation rate $q^{*}$ of the demand side management service application under normally and uniformly distributed unobserved preferences. Given the positive network externality function $f(q)$ shown in Figure 2, the fixed point $q^{*}$ is a function of platform price $p$

$$
q^{*}=\Phi\left(-p+f\left(\mathrm{q}^{*}\right)\right)
$$

where $\Phi$ is the cumulative distribution function of unobserved preferences $\varepsilon$.

Figure 12 shows the fixed points (located on the $45^{\circ}$ line) for varying platform prices, when unobserved preferences are normally distributed (references scenario in Figure 3). With lower platform price $p$, the equilibrium participation rate $q^{*}$ increases.

Figure 13 shows the fixed points (located on the $45^{\circ}$ line) for varying platform prices, when unobserved preferences are uniformly distributed (Scenario 2 in Figure 4). With lower platform price $p$, the equilibrium participation rate $q^{*}$ increases. Compared to normal distribution, the equilibrium participation rate under uniform distribution is more sensitive to platform price increase from $p=40$. On the other hand, the equilibrium participation rate under uniform distribution is less sensitive to platform price decrease from $p=-20$.

Open Access This article is licensed under a Creative Commons Attribution 4.0 International License, which permits use, sharing, adaptation, distribution and reproduction in any medium or format, as long as you give appropriate credit to the original author(s) and the source, provide a link to the Creative Commons licence, and indicate if changes were made. The images or other third party material in this article are included in the article's Creative Commons licence, unless indicated otherwise in a credit line to the material. If material is not included in the article's Creative Commons licence and your intended use is not permitted by statutory regulation or exceeds the permitted use, you will need to obtain permission directly from the copyright holder. To view a copy of this licence, visit http://creativecommons.org/licenses/by/4.0/. 


\section{References}

1. Armstrong, M. (2006). Competition in two-sided markets. The Rand Journal of Economics, 37, 353-380.

2. Broberg, T., \& Persson, L. (2016). Is our everyday comfort for sale? Preferences for demand management on the electricity market. Energy Economics, 54, 24-32.

3. Cabral, L. (2011). Dynamic price competition with network effects. Review of Economic Studies, 78, 83-111.

4. Doganoglu, T. (2003). Dynamic price competition with consumption externalities. Netnomics, 5, 43-69.

5. Dütschke, E., \& Paetz, A.-G. (2013). Dynamic electricity pricing - Which programs do consumers prefer? Energy Policy, 59, 226-234.

6. Evans, D. S., \& Schmalensee, R. (2010). Failure to launch: Critical mass in platform business. Review of network economics, 9.4, article 1, 26 pages. Retrieved mar 2020 https://doi.org/10.2202/1446-9022.1256.

7. Finlex (2009). Valtioneuvoston asetus sähköntoimitusten selvityksestä ja mittauksesta. https://www. finlex.fi/fi/laki/alkup/2009/20090066\#Lidp447452224 Accessed 11th of Feb, 2020.

8. Fudenberg, D., \& Tirole, J. (2000). Pricing under the threat of entry by a sole supplier of a network good. Journal of Industrial Economics, 48, 373-390.

9. Gowrisankaran, G., Reynolds, S., \& Samano, M. (2016). Intermittency and the value of renewable energy. Journal of Political Economy, 124, 1187-1234.

10. Greene, W. (2005a). Reconsidering heterogeneity in panel data estimators of the stochastic frontier model. Journal of Econometrics, 126, 269-303.

11. Greene, W. (2005b). Fixed and random effects in stochastic frontier models. Journal of Productivity Analysis, 23, 7-32.

12. Hirth, L., Ueckerdt, F., \& Ottmar, E. (2015). Integration costs revisited - An economic framework for wind and solar variability. Renewable Energy, 74, 925-939.

13. Huuki, H., Karhinen, S., Kopsakangas-Savolainen, M., \& Svento, R. (2020). Flexible demand and supply as enablers of variable energy integration. Journal of Cleaner Production, 285, 120574.

14. Kopsakangas-Savolainen, M., \& Svento, R. (2012). Modern energy markets. London: Springer.

15. Markovich, S., \& Moenius, J. (2009). Winning while losing: Competition dynamics in the presence of indirect network effects. International Journal of Industrial Organization, 27, 346-357.

16. McPherson, M., \& Stoll, B. (2020). Demand response for variable renewable energy integration: A proposed approach and its impacts. Energy, 197, 117205.

17. Mitchell, M., \& Skrzypacz, A. (2006). Network externalities and long-run market share. Economic Theory, 29, 621-648.

18. Nord Pool (2020). https://www.nordpoolgroup.com/historical-market-data/. Accessed $2^{\text {nd }}$ of Feb, 2020.

19. Richter, L.-L., \& Pollit, M. (2018). Which smart electricity service contract will consumers accept? The demand for compensation in a platform market. Energy Economics, 72, 436-450.

20. Rochet, J.-C., \& Tirole, J. (2003). Platform competition in two-sided markets. Journal of European Economic Association, 1, 990-1029.

21. Rochet, J.-C., \& Tirole, J. (2006). Two-sided markets: A progress report. The Rand Journal of Economics, 37, 645-667.

22. Rolfs, J. (1974). A theory of interdependent demand for a communications service. Bell Journal of Economics and Management Science, 5, 16-37.

23. Ruokamo, E., Kopsakangas-Savolainen, M., Meriläinen, T., \& Svento, R. (2019). Towards flexible energy demand - Preferences for dynamic contracts, services and emissions reductions. Energy Economics, 84, 104522.

24. Schlereth, C., Skiera, B., \& Schulz, F. (2018). Why do consumers prefer static instead of dynamic pricing plans? An empirical study for a better understanding of the low preferences for time-variant pricing plans. European Journal of Operational Research, 269, 1165-1179.

25. Shapiro, C. \& Varian, H. R. (1999). Information rules: A strategic guide to the network economy. Harvard Business School Press, Boston. ISBN-0-87584-863-X.

26. Train, K. (2009). Discrete choice methods with simulation. Cambridge Core. Cambridge University Press. https://doi.org/10.1017/CBO9780511805271.

27. Veiga, A. (2014). Dynamic platform design. In Working papers 14-15. NET Institute. Retrieved Aug 2019, https://ideas.repec.org/p/net/wpaper/1415.html.

28. Weiller, C. M. and Pollitt, M. G. (2013). Platform markets and energy services. Cambridge Working Papers in Economics 1361, Faculty of Economics, University of Cambridge.

29. Weyl, E. G. (2010). A Price Theory of Multi-sided Platforms. American Economic Review, 100 (4), $1642-72$.

30. Zhu, F., \& Iansiti, M. (2007). Dynamics of platform competition: Exploring the role of installed base, platform quality and consumer expectations. Working paper no. 08-031, Harvard Business School. 